\title{
A PRODUÇÃO ESCRITA EM SALA DE AULA DE PORTUGUÊS COMO LÍNGUA ESTRANGEIRA/SEGUNDA LÍNGUA: QUANDO E COMO INTERVIR
}

\author{
LA PRODUCCIÓN ESCRITA EN AULA DE CLASE DE PORTUGUÉS COMO LENGUA \\ EXTRANJERA/SEGUNDA LENGUA: CUÁNDO Y CÓMO INTERVENIR?
}

\author{
WRITTEN PRODUCTION IN PORTUGUESE AS A FOREIGN LANGUAGE/SECOND \\ LANGUAGE CLASSROOM: WHEN AND HOW TO INTERVENE
}

Sara Oliveira da CRUZ ${ }^{1}$

RESUMO: Uma das preocupações mais recorrentes dos professores de Português como Língua Estrangeira/Segunda Língua (PLE/L2), principalmente nos estágios iniciais da sua formação docente, abrange a correção das produções escritas. O objetivo deste trabalho é apresentar aspectos que envolvam a "correção" das produções textuais de estudantes de PLE/L2 e discutir quando e como intervir nessas produções, com base nos dados apresentados na investigação de Cruz (2019), os quais foram gerados a partir das observações de aulas e entrevistas realizadas com todos(as) os(as) participantes; da implementação de um conjunto de atividades e também dos relatórios de estágio do(a)s professore(a)s em formação. Inicialmente, apresenta-se as concepções de língua/linguagem e de ensino-aprendizagem que conduziram e conduzem as ações da pesquisadora fora e dentro da sala de aula; em seguida, discute-se aspectos que podem envolver a "correção" das produções textuais supracitadas e, por fim, apresenta-se algumas proposições para a intervenção do(a) professor(a) nas produções escritas.

PALAVRAS-CHAVE: Português Língua Estrangeira/Segunda Língua (PLE/PL2). Formação inicial de professores. Produção textual.

RESUMEN: Una de las preocupaciones más recurrentes de los profesores de Portugués como Lengua Extranjera/Segunda Lengua (PLE/L2), principalmente en los años iniciales de su formación docente, cubre la corrección de las producciones escritas. El objetivo de este trabajo es presentar aspectos que involucren la "corrección" de las producciones textuales de estudiantes de PLE/L2 y discutir cuándo y cómo intervenir en esas producciones, basados en los datos presentados en la investigación de Cruz(2019), los cuales fueron generados a partir de las observaciones de clases y entrevistas realizadas con todos(as) los (las) participantes; de la implementación de un conjunto de actividades y también de un informe de pasantías de los profesores y profesoras en formación. Inicialmente, se presenta las concepciones de lengua/lenguaje y de enseñanza-aprendizaje que condujeron y conducen las acciones de la investigadora fuera y dentro del aula de clase; luego, se discute aspectos que pueden envolver la "corrección" de las producciones textuales habladas anteriormente y, por

${ }^{1}$ Universidade Federal da Bahia (UFBA), Salvador - BA - Brasil. Programa de Pós-Graduação em Língua e Cultura. Núcleo de Estudos em Língua, Cultura e Ensino (Lince/CNPQ) e Observatório de Português Língua Estrangeira/Segunda Língua (ObsPLE-PL2, CNPQ). Mestrado em Língua e Cultura, na área de Linguística Aplicada, especialista em Educação a Distância e graduada em Letras Vernáculas e Português como Língua Estrangeira. ORCID: https://orcid.org/0000-0001-9886-1762. E-mail: oliveira.kid@gmail.com 
fin, se presenta algunas proposiciones para la intervención de las profesoras y profesores en las producciones escritas de los dicentes.

PALABRAS CLAVE: Portugués Lengua Extranjera/Segunda Lengua (PLE/PL2). Formación inicial de profesores. Producción Textual.

ABSTRACT: One of the recurring concerns of Portuguese as Foreign Language/Second Language (PFL/PSL) teachers, especially in the early stages of their teacher training, encompasses the correction of written production. The objective of this work is to present aspects that involve the "correction" of textual productions of PFL/PSL students and discuss when and how to intervene in these productions, based on data presented in Cruz (2019), which were generated from the observations of classes and interviews carried out with all participants; the implementation of a set of activities and also the internship reports of the trainee teachers. Initially, this article presents the concepts of language, teaching, and learning that led and lead the researcher's actions outside and inside the classroom; then, it discusses aspects that may involve the "correction" of the aforementioned text productions and, finally, the work presents some proposals for the intervention of the teacher in the written productions.

KEYWORDS: Portuguese as a Foreign Language/Second Language (PFL/PSL). Initial teacher training. Text production.

\section{Introdução}

Uma das preocupações mais recorrentes dos professores de Português como Língua Estrangeira/Segunda Língua (PLE/L2), principalmente nos estágios iniciais da sua formação docente, envolve aspectos relacionados a "como, quando e o que se deve ou não corrigir nas produções escritas dos estudantes de PLE/L2”. Esses foram alguns dos questionamentos que surgiram durante o desenvolvimento de uma pesquisa de mestrado realizada com estudantes da graduação do Curso de Licenciatura em Português Língua Estrangeira/Segunda Língua da Universidade Federal da Bahia, que, em sua maioria, estavam cursando a disciplina de Estágio Supervisionado I de Português como Língua Estrangeira dessa licenciatura (CRUZ, 2019).

O objetivo deste artigo é apresentar aspectos que envolvam a "correção" das produções textuais de estudantes de Português como Língua Estrangeira/Segunda Língua (PLE/L2) e discutir quando e como intervir nessas produções, com base nos dados apresentados na investigação de Cruz (2019), os quais foram gerados a partir das observações de aulas e entrevistas realizadas com todos(as) os(as) participantes; da implementação de um conjunto de atividades e também dos relatórios de estágio do(a)s professore(a)s em formação. 
Inicialmente, assinalo as concepções de língua/linguagem e de ensino-aprendizagem que têm conduzido as minhas ações fora e dentro da sala de aula, por compreender que essa reflexão inicial é necessária para discussão desses aspectos, posteriormente, apresento algumas proposições acerca da intervenção do(a) professor(a) nas produções escritas.

\section{Reflexões iniciais}

Atualmente, firmo-me na concepção de língua-cultura. ${ }^{2}$ Nessa visão de língua/linguagem, a língua-cultura é, mais do que tudo, uma prática social, uma atividade, uma ação desempenhada pelos sujeitos que interagem através dela, uma rede complexa que considera não apenas sua dimensão linguística, mas também as dimensões sociocultural, histórica e política. Nas palavras de Mendes (2008, p. 72), "Língua que mais do que parte da dimensão cultural, ela é a própria cultura, se confunde com ela".

Nesse sentido, também me valho de uma perspectiva de ensino-aprendizagem de línguas que me provoca a desbravar contextos complexos e multilíngues, marcados pela diversidade, pela desigualdade e, muitas vezes, pela injustiça social, e que me ajuda a escolher, com autonomia e consciência crítica, a(s) representação(ões) de língua/linguagem que estará(ão) na base das minhas ações ${ }^{3}$. Rayo assevera que:

Hoje em dia, devido aos grandes avanços dos meios de comunicação, aos movimentos migratórios, aos contatos internacionais, ao turismo, à mundialização da economia, e a outros fatores, exige-se uma ação educativa nesta direção. A própria ideia de Europa de povos unidos requer a aceitação do pluralismo cultural e a urgência de ações educativas interculturais (RAYO, 2004, p. 69).

Nessa mesma direção, Souza e Fleuri destacam que:

A educação intercultural se preocupa com as relações entre seres humanos culturalmente diferentes uns dos outros. Não apenas na busca de apreender o caráter de várias culturas, mas, sobretudo, na busca de compreender os sentidos que suas ações assumem no contexto de seus respectivos padrões culturais e na disponibilidade de se deixar interpelar pelos sentidos de tais ações e pelos seus significados constituídos por tais ações e pelos significados constituídos por tais contextos" (SOUZA; FLEURI, 2003, p. $68)$.

Acreditando na necessidade - para não dizer urgência - de construirmos espaços de interlocução, de compartilhamento e construção ativa, incessante de conhecimentos, de

${ }^{2}$ Ver Mendes (2008).

${ }^{3}$ Para saber mais sobre a perspectiva da educação interculturalmente sensível, ler Mendes (2011). 
respeito às diferenças, bem como de construir um conjunto de práticas que deem conta de diferentes problemas do nosso mundo contemporâneo, os quais são refletidos nas nossas salas de aula, torna-se fundamental a luta constante contra todo tipo de injustiça social, discriminação e racismo. Para isso, precisamos, como nos diz Mendes, "contribuir para a criação dessas zonas fronteiriças, desses espaços "inter", "entre" ou os entrelugares, "terceiros lugares". (MENDES, 2011, p. 142). Essa autora, mencionando Bhabha (MENDES 1998, 2011, p. 141), destaca que esse "terceiro lugar" é marcado "pela tensão constante entre sujeitos-mundos diferentes e que, como todo ambiente de produção e troca de significados, alimenta-se e reestrutura-se a partir dessa própria tensão-negociação-troca".

Dito isso, a perspectiva intercultural na qual acredito busca ser crítica, decolonial e olhar para elementos suleadores e contra-hegemônicos. Por isso que:

[...] a educação intercultural não pode ser reduzida a algumas situações e/ou atividades realizadas em momentos específicos, nem focalizar sua atenção exclusivamente em determinados grupos sociais. Trata-se de um enfoque global que deve afetar todos os atores e todas as dimensões do processo educativo, assim como os diferentes âmbitos em que ele se desenvolve. No que diz respeito à escola, afeta a seleção curricular, a organização escolar, as linguagens, as práticas didáticas, as atividades extraclasse, o papel do/a professor/a, a relação com a comunidade etc. (CANDAU, 2008, p. 170).

Nesse viés:

O desenvolvimento de uma abordagem que se pretende intercultural para o ensino/aprendizagem de LE/L2, antes de ser um exercício de construção teórica, deve obedecer a um criterioso processo de planejamento e estruturação, o qual envolve desde o estabelecimento dos princípios norteadores da ação pedagógica, até o planejamento de cursos, seleção e produção de materiais didáticos e elaboração de estratégias de monitoramento e avaliação, sempre tendo em vista qual é o público ao qual se destina a ação pedagógica, em que contexto ou contextos e sob que condições (MENDES, 2004, p. 115).

É com esse arcabouço conceitual, o qual está aberto à construção e edificação de um conjunto de temáticas e de práticas decoloniais, suleadoras e contra-hegemônicas, que sigo refletindo sobre a prática pedagógica, a produção de materiais didáticos, as diferentes salas de aula de PLE/L2 e o nosso estar no mundo com os(as) nossos(as) alunos(as).

Quem busca atuar em uma perspectiva intercultural, portanto, precisa estar atento(a) aos problemas que surgem na relação entre sujeitos de diferentes línguas-cultura, os quais acabam não só refletindo na sala de aula, mas em todos os elementos que constituem a educação linguística de um modo geral. Também precisa se perceber (e se tornar) agente da 
interculturalidade ${ }^{4}$, para, assim, contribuir com a resolução de diferentes problemas que ainda persistem ou surgem na contemporaneidade.

Refletir acerca das concepções de língua/linguagem e de ensino-aprendizagem que têm conduzido as minhas ações fora e dentro da sala de aula possibilitou-me compreender um pouco mais a minha prática docente e os passos que me trouxeram até o desenvolvimento deste trabalho.

\section{Produção textual: Inquietudes dos professores em formação de PLE/L2}

Para a geração de dados da pesquisa, frequentei três aulas da turma de Estágio Supervisionado I de Português como Língua Estrangeira ${ }^{5}$. No terceiro encontro, conversamos sobre o tema "Correções de textos escritos: Corrigir ou não corrigir? Quando, o quê, como devemos corrigir os textos escritos dos alunos?". Essa discussão foi necessária porque esses questionamentos foram realizados em momentos distintos pelos(as) professores(as) em formação que estavam cursando essa disciplina e que aceitaram participar da pesquisa.

No primeiro encontro que tive com essa turma, Haiti $^{6}$ foi o primeiro a conversar comigo sobre esse tema. Após a aula, ele quis saber o que eu pensava sobre a abordagem que orienta a exposição do aluno à língua, sem a intervenção do professor apontando os erros/desvios cometidos, também ele quis saber se, no turno da fala dos(as) alunos(as), eu os corrigia.

Ele revela ter dúvidas com relação a essa abordagem e que acha muito complicado “isso de deixar o aluno solto, sem nenhuma orientação", já que, segundo essa abordagem, o aluno, em um determinado momento, seria capaz de perceber o que é adequado/correto na língua, ou seja, na interação, os aprendizes perceberiam os "erros" que estão cometendo e fariam as correções necessárias ${ }^{7}$. Conversamos sobre algumas abordagens de ensinoaprendizagem de línguas, especialmente sobre as Abordagens Comunicativa e Intercultural.

\footnotetext{
${ }^{4}$ Refiro-me aos modos como podemos agir na interação com outro e nas práticas de ensinar e aprender língua em direção à construção de experiências interculturais. Ser agente da interculturalidade é possibilitar efetivamente um diálogo intercultural que permita com que esses sujeitos se encontrem em situações reais de uso da língua e que tenham a oportunidade de conhecer a si e o outro e de compreender, por meio desse diálogo, a língua e a cultura que se co-constroem na interação. Para saber mais, ler Mendes (2012).

${ }^{5}$ Componente curricular da licenciatura em PLE do ILUFBA.

${ }^{6}$ Para preservar a identidade dos oito professores(as) em formação de PLE que participaram da pesquisa, optei por nomeá-los(las) com os nomes dos países ou continentes correspondentes à origem da maior parte dos seus alunos, a saber: Benim, Gabão, Gana, República Democrática do Congo, Haiti, África, América, Europa.

${ }^{7}$ Quando entrevistei África, ela declarou que, embora tenha sido orientada a não corrigir os(as) alunos(as) no turno de fala deles(as), procurava sempre lhes apontar os "erros" e ainda questiona "como eles vão corrigir os "erros" se não sabem identificá-los?".
} 
Sugeri que pesquisasse um pouco mais sobre esse tema, uma vez que esses questionamentos estavam vindo à tona.

Após o segundo encontro com essa turma, encontrei Haiti a caminho do ponto de ônibus e ele me perguntou se eu tinha alguma Unidade Temática (UT) impressa, pois gostaria de aplicá-la ${ }^{8}$. Ele escolheu uma das unidades e, em seguida, perguntou-me "É só seguir o roteiro, né?". Disse-lhe que a condução da aula ficaria a seu critério e que o roteiro era apenas uma sugestão, que ele tinha total liberdade de fazer o que e como quisesse, mas que a última atividade da UT sugeria a produção de uma campanha contra o racismo e a xenofobia, em formato de vídeo, e que, durante o processo de produção, os alunos poderiam elaborar algum texto escrito. Nesse momento, Haiti indaga-me "Aí caímos naquela situação 'corrigir ou não corrigir?'.

Essa preocupação surge também com outros(as) professores(as) em formação. Congo e Benin, por exemplo, quando os(as) alunos(as) estavam realizando a produção escrita da unidade "Como é a sua rotina", questionaram-me se deveriam corrigir os textos produzidos pelos(as) alunos(as).

A fim de elucidar essas questões e incentivar essa discussão, no terceiro encontro, apresentei alguns comentários produzidos pelos(as) meus(minhas) ex-alunos(as) e pelos(as) alunos(as) das tutoras (os quais estão disponíveis no blog Vivendo no Brasil ${ }^{10}$ ). Nesse encontro, cada professor em formação recebeu um desses comentários, analisou-os e, em seguida, compartilhou com a turma o seu parecer.

Nesse encontro, estavam presentes nove professores em formação. Um deles atuava no Programa Especial de Monitoria de Português como Língua Estrangeira (PROEMPLE) como monitor, os demais eram tutores nesse programa ${ }^{11}$. Estes ressaltavam que os(as) alunos(as) atenderam ao comando cobrado na atividade (responder à postagem) e demonstraram ter compreendido o texto da postagem, embora seus comentários não apresentassem, em sua maior parte, pontuação adequada, presença e uso adequado de conectivos e preposições;

${ }^{8} \mathrm{O}$ principal objetivo desses dois primeiros encontros era apresentar minha pesquisa e convidá-los(as) para participar dela. Naquele momento, apresentei-lhes três Unidades Temáticas: "Como é a sua Rotina", "Preconceito" e "Racismo", trata-se de um conjunto de atividades que desenvolvi durante a etapa de geração de dados para ser implementando pelos professores em formação nas suas aulas de PLE.

9 A atividade de produção escrita sugeria a produção de uma postagem a ser publicada no blog Falando Português sobre o tema "Minha vida no Brasil.

${ }^{10}$ www.vivendonobrasil.blogspost.com.

11 O PROEMPLE é um subprograma do Programa de Proficiência em Língua Estrangeira para Estudantes e Servidores da UFBA (PROFICI), que se dedica, desde 2014, a ofertar cursos de PLE a alunos estrangeiros com matrícula regular em nível de graduação e pós-graduação e cidadãos(ãs) de países em desenvolvimento com os quais o Brasil mantém acordos educacionais e culturais. Para saber mais detalhes sobre a monitoria e a tutoria, ver Cruz (2019, p. 53-55). 
ademais, o sentido, em alguns trechos, apresentou algum comprometimento. Eles(as) avaliaram que, usando as palavras de um(a) dos(as) professores(as), "eles estão indo bem e de repente querem dizer uma coisa que não sabem o significado, como se diz, e aí, eles vão tentando adequar para o que eles acham, mas a frase acaba perdendo o sentido".

Para que os(as) alunos(as) se atentassem a esses aspectos, Gabão sinaliza que corrigiria os erros de concordância e outros aspectos gramaticais (falta de coesão), já que eles(as) estão em processo de aquisição e, no semestre seguinte, fariam o Exame de Certificação de Proficiência em Língua Portuguesa para Estrangeiros (Celpe-Bras). Nessa mesma linha de raciocínio, outro(a) professor(a ${ }^{12}$ compartilha que buscaria orientá-los(as) a escrever um texto um pouco mais formal, por exemplo, trabalhando com pontuação, coesão, construção de períodos mais curtos, fechamento de ideias e uso de palavras de contraste porém, contudo - que alguns deles já usam, mas "meio fora de sentido".

Congo menciona que, ao aplicar a UT, preferiu não corrigir o comentário durante a aula por entender que aquele era um espaço de aprendizagem e, depois, o aluno poderia, no futuro, ver como escrevia, além de também considerar que um blog - ambiente informal de uso da linguagem - lhe permitiria escrever daquela forma.

No final desse encontro, o(a) último(a) professor(a) em formação a se expor diz que, em relação aos conectivos, locuções conjuntivas, conjunções, pontuação, acredita que isso não dificultou o entendimento do texto, pois o professor conseguiria ler e colocar a pontuação. Ele(a) acredita que seria mais produtivo e melhor para os(as) alunos(as) se focássemos "na facilitação, na maneira em que a pessoa emite, na forma como a pessoa expressa a sua ideia, em vez de focarmos em pontuação".

No seu ponto de vista, isso pode ser feito de uma maneira reflexiva, lançando as seguintes perguntas para o(a) aluno(a): "Você acha que você se fez entender bem, você acha que os seus colegas estão entendendo o que você está falando?"; pedindo para que eles(as) perguntem aos colegas se o texto está compreensível e para que leiam os seus textos para os(as) colegas da turma. Ele(a) acredita que não lhe cabe dizer para o(a) aluno(a) se aquilo que foi dito (escrito/falado) é ou não compreensível, já que não acredita na ideia de que "eu tenho a língua, vou te passar".

Como mencionado por Congo, esse(a) professor(a) em formação também comenta que o comentário foi postado em um blog, e o ambiente da internet permite ao(à) aluno(a) escrever daquela forma, bastaríamos ver como os próprios brasileiros utilizam o ambiente

\footnotetext{
${ }^{12}$ Não o(a) nomeio, pois esse(a) professor em formação não participou efetivamente da pesquisa.
} 
virtual. Para ele(a), talvez esses aspectos analisados não reflitam, de fato, um problema de aprendizado de português, pois não sabemos como foi a escolarização desses(as) alunos(as) até chegarem aqui. Ele(a) revela que isso tem despertado muito sua atenção no PROEMPLE e sente vontade de pedir que seus(suas) alunos(as) escrevam o primeiro texto em língua materna ("Escreva aí qualquer coisa no seu idioma"), para, dessa maneira, identificar se o(a) aluno(a) comete os mesmos erros/desvios ao usar a língua materna.

À medida que os professores em formação iam expondo as suas percepções, eu também acabava expondo aquilo em que eu acreditava. Apresentei de que forma poderíamos abordar os aspectos gramaticais e pragmáticos da língua a partir daquelas produções, visto que, em vários momentos desse encontro, um(a) dos(as) professores(as) em formação ${ }^{13}$ fez, em momentos distintos, os comentários expostos, a seguir, nos excertos [1] e [2]:

\section{Excerto [1]}

Eu gostei do texto, tendo em vista, não tendo a importância estruturalista da coisa, mas eu acho que deu para entender, compreender. Essa questão de vírgula, pontuação, eu acho normal. Então, eu não vejo, na verdade, eu acho que não enxergo nada que eu possa trabalhar com ele, eu tenho que olhar isso, pois, talvez, eu precisasse de um estudo, da orientação para que eu pudesse, de certa forma, promover essa instrução a ele. (Anotações no diário de campo).

Nessa análise, o(a) professor(a) reflete que, embora tenha gostado do texto e pontuado alguns aspectos estruturais os quais, naquele momento, considere como desvios normais de uso, necessita de um estudo, de uma orientação para aprender a instruir melhor os alunos. Esse(a) foi o(a) segundo(a) professor(a) em formação a ler e a analisar os comentários postados dos alunos no blog. No decorrer da atividade, após outros textos também serem lidos e analisados, ele(a) questiona:

\section{Excerto [2]}

Só aproveitando aqui porque eu já vi aqui que alguns textos estão nessa mesma linha. Perceba que têm erros aqui que a gente identifica, erros, inadequações, que a gente percebe certas inadequações. Mas, por exemplo, para mim, eu tenho uma dificuldade muito grande de como trabalhar essas coisas. Vocês não passam por isso não, gente? Ou é só impressão minha, pessoal? [...] Não com gramática, têm certas inadequações clássicas que são normais, são inadequações, isso aí a gente não tem dúvida, mas como trabalhar com sentidos, eu não sei. (Anotações no diário de campo).

${ }^{13}$ Não o(a) nomeio, pois esse(a) professor(a) em formação não participou efetivamente da pesquisa. 
Observo, aqui, que esse(a) professor(a) em formação dá-se conta de um aspecto que precisa ser trabalhado em sala de aula: o texto e a construção dos sentidos. Como se viu, ele(a) assume ter muita dificuldade de como seria essa abordagem e interpela os(as) colegas da turma querendo saber se eles(as) também passam por essa mesma situação.

Esse breve (mas significativo) relato desses três encontros com os(as) professores(as) em formação de PLE/PL2 revelam algumas inquietações dos(as) professores(as), sobretudo daqueles que estão nos estágios iniciais da sua formação docente, e o desejo de aprender a orientar da melhor maneira possível a produção textual dos(as) seus(suas) alunos(as) de PLE/PL2. Acredito que os principais aspectos que envolvem a "correção" das produções textuais dos alunos foram emanados nessa atividade de leitura e análise de produções escritas de alunos de PLE.

Afinal, quando e como intervir. Em linhas gerais, diante do que pude discutir até aqui, a intervenção do(a) professor(a) deve ocorrer quando:

Figura 1 - Intervenção do(a) professor(a)

1. $O$ (A) aluno(a) realiza superficialmente ou muito superficialmente ou não realiza a ação
solicitada no enunciado/comando da atividade.
2. $O(A)$ aluno(a) não cumpri o(s) propósito(s) exigido(s) no enunciado/comando da atividade.
3. O aluno(a) apresenta dificuldade para produzir o texto no gênero discursivo solicitado.
4. O aluno(a) não usa ou usa parcialmente os recursos linguísticos esperados para o determinado
nivel de proficiência.
5. A construção de sentidos está parcialmente ou seriamente comprometida.
6. Há truncamentos de periodos e/ou justaposições de orações comprometendo a fluidez da leitura.
7. Há interferência(s) de outra(s) língua(s) no texto.

Fonte: Acervo das autoras

Ao identificar algum desses cenários ${ }^{14}$, é importante verificar e/ou investigar se foram fatores externos ou internos à produção escrita que ocasionaram a(s) situação(ões) supracitada(s), pois, a intervenção poderá ser diferente a depender da(s) situação(ões).

Para realizar a verificação de fatores externos ao texto, o(a) professor(a) poderá seguir o fluxo apresentado a seguir.

${ }^{14}$ É importante dizer que a elaboração desses cenários e dos fluxogramas apresentados a seguir também tem como base os critérios de avaliação da parte escrita do Celpe-Bras (BRASIL, 2020b) e da redação do ENEM (BRASIL, 2020a). 
Figura 2 - Verificação de fatores externos

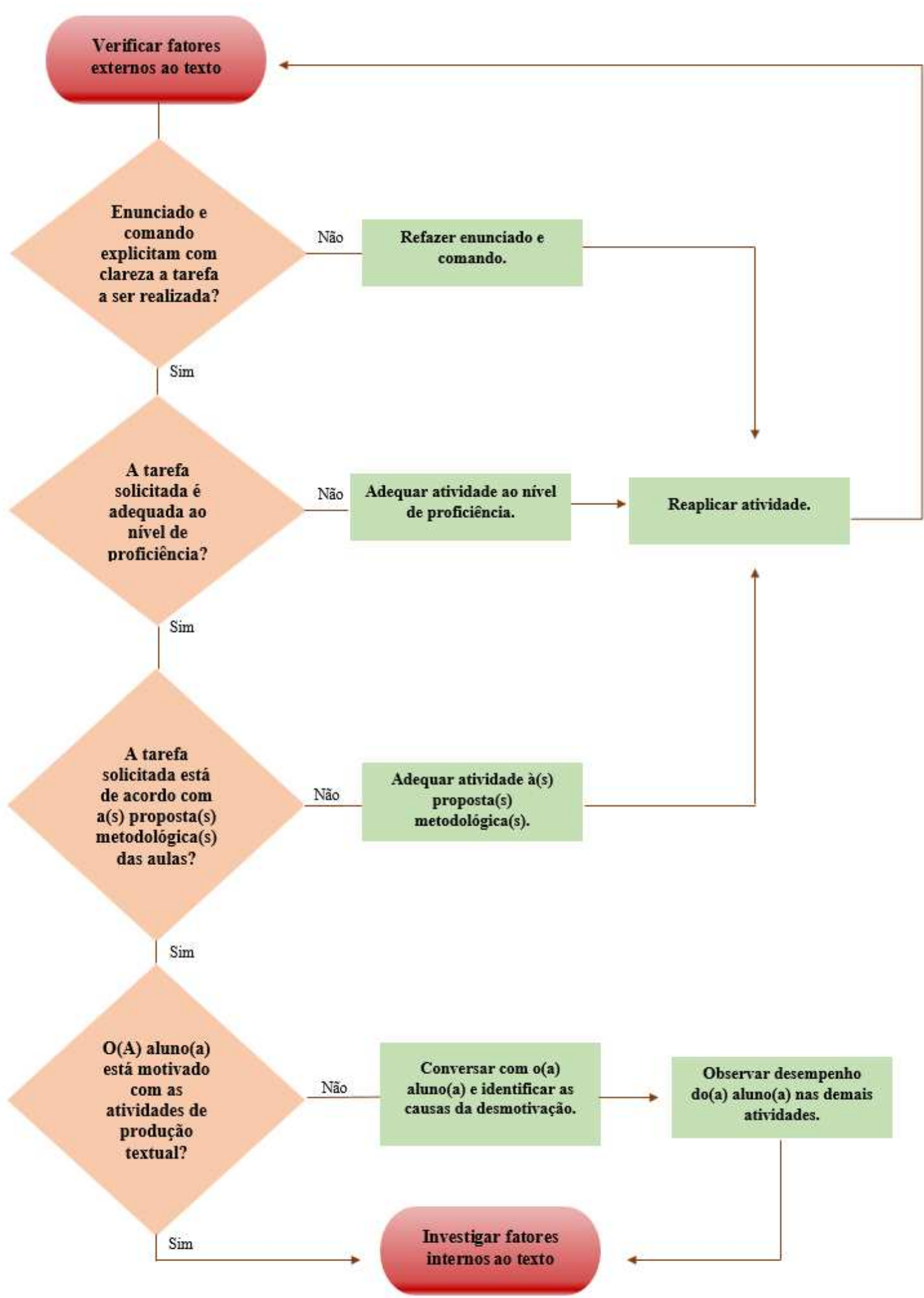

Fonte: Acervo das autoras 
A Figura 2, como vimos, apresenta um fluxograma com quatro situações que podem limitar o processo de produção textual do aluno e com ações que podem ser realizadas pelo(a) professor(a) para reparar "erros" recorrentes na elaboração desse tipo de atividade. Compreendo que aspectos externos ao texto produzido pelo(a) aluno(a) podem ser fatores que podem levá-lo(a) a realizar superficialmente ou muito superficialmente ou não realizar a ação solicitada no enunciado da atividade e/ou a não cumprir o(s) propósito(s) exigido(s) no enunciado da atividade.

Além dessas, identifiquei outras situações que podem (ou não) comprometer o desempenho do(a) aluno(a) na atividade, cabendo ao(à) professor(a) a tarefa de investigar os fatores internos à produção escrita, bem como, a depender da situação, as suas variáveis.

Para iniciar a investigação desses fatores, o(a) professor(a) poderá seguir o fluxo apresentado a seguir.

Figura 3 - Investigação de fatores internos ao texto

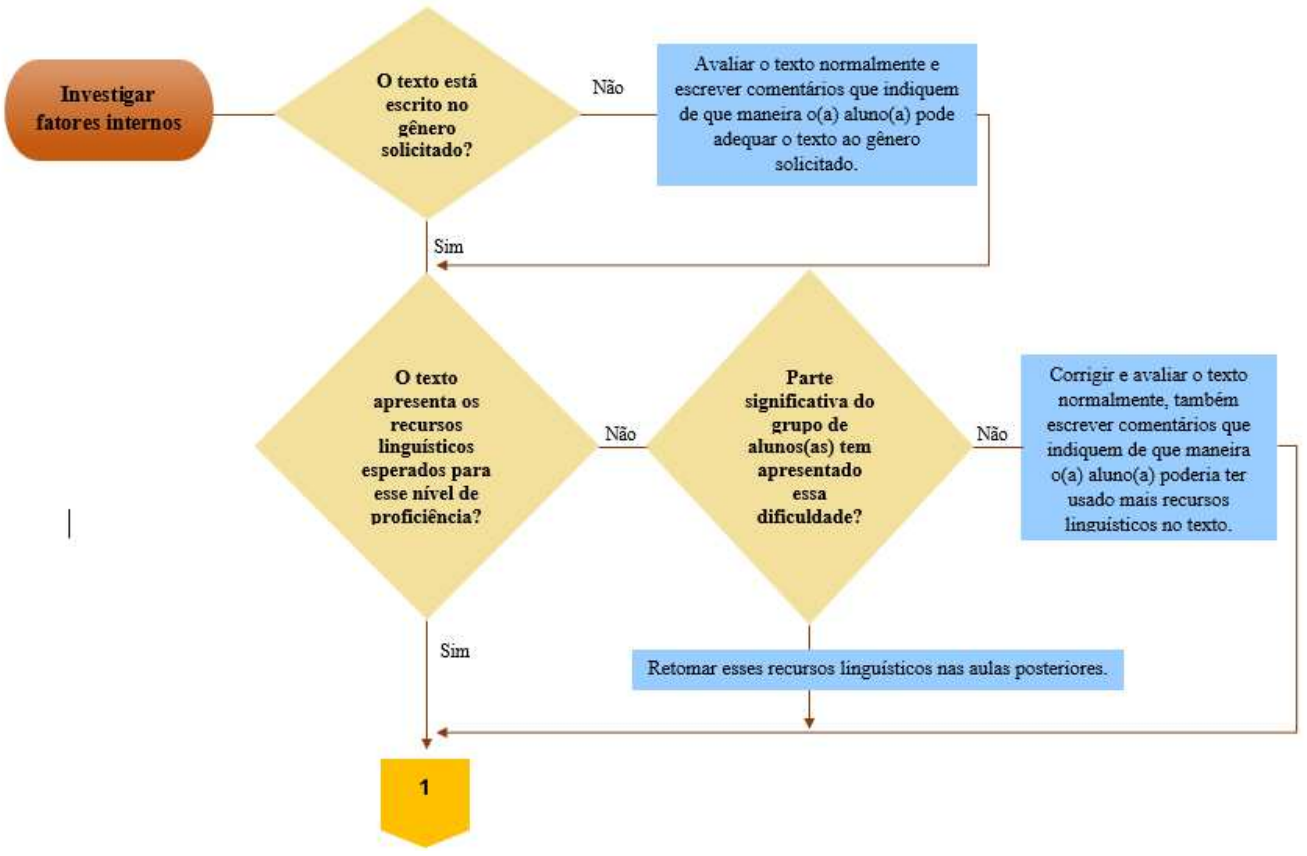

Fonte: Acervo das autoras 
Figura 4 - Investigação de fatores internos ao texto

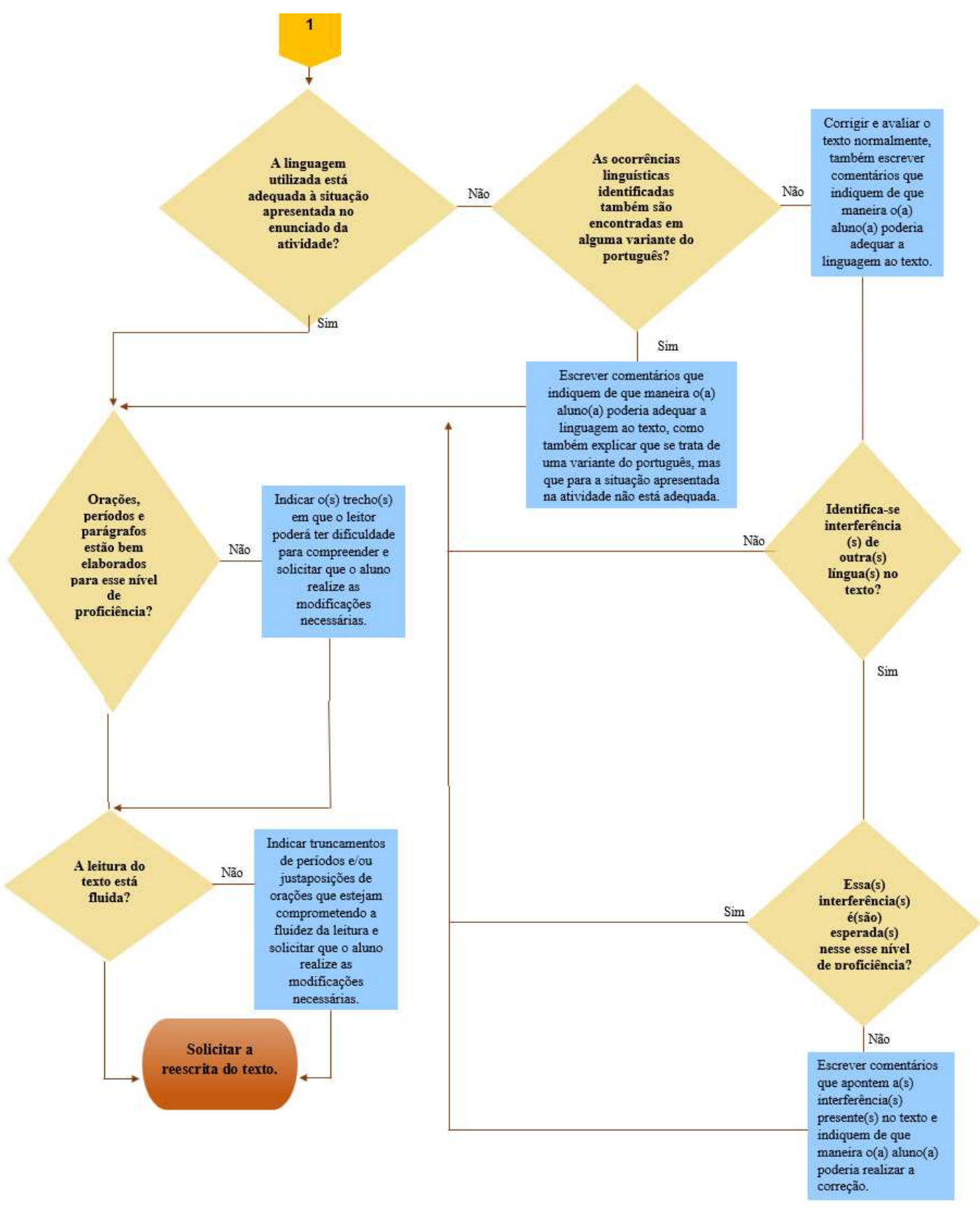

Fonte: Acervo das autoras

Vimos, na Figura 3, um fluxograma que procura explorar fatores que dizem respeito à produção do texto no gênero discursivo solicitado, ao uso de recursos linguísticos esperados para o determinado nível de proficiência, à construção de sentidos, à fluidez da leitura e à interferência(s) de outra(s) língua(s). Acredito que esse material pode ajudar o(a) professor(a) de PLE/L2, principalmente nos estágios iniciais da sua formação docente, a refletir nas ações 
que podem ser desempenhadas durante o processo de correção das produções escritas dos(as) seus(suas) alunos(as).

Esses são alguns dos principais aspectos que podem envolver a "correção" das produções textuais dos(as) alunos(as), que surgiram durante a leitura e análise de produções escritas de alunos de PLE, com os professores em formação de PLE. Temos, aqui, uma contribuição inicial e que, portanto, esses aspectos precisam ser aprofundados.

\section{Considerações finais}

Com base nos dados gerados na investigação de Cruz (2019), pesquisa realizada com estudantes da graduação do Curso de Licenciatura em Português Língua Estrangeira/Segunda Língua da Universidade Federal da Bahia que revelou, entre outros aspectos, o desejo desses(as) professores(as) em aprender a orientar da melhor maneira possível a produção textual dos(as) seus(suas) alunos(as) de PLE/L2, procurei, neste trabalho, apresentar alguns cenários e, por meio de dois fluxogramas, incentivar a verificação e a investigação de fatores externos ou internos à produção escrita que podem limitar o processo de produção textual do aluno e/ou comprometer o desempenho do(a) aluno(a) na atividade, propondo ações que podem ser realizadas pelo(a) professor(a) para reparar "erros" recorrentes nesse processo. Essas ações podem evitar a:

Elaboração de atividades de produção escrita com o objetivo de avaliar apenas a superfície do texto. Nessa ação, evidencia-se a ideia de texto como pretexto para correção de gramática.

Elaboração de atividades sem que os critérios de avaliação tenham sido definidos. Os critérios de avaliação devem ser coerentes com as ações e habilidades desenvolvidas e com os conteúdos abordados no decorrer do curso, além de estarem alinhados ao nível de proficiência em questão. É importante que esses critérios sejam apresentados aos(às) alunos(as).

Correção seja um momento de avaliar as ideias, os pensamentos, as experiências compartilhas pelo(a) o(a) aluno(a). Um(a) professor(a) que busca atuar em uma perspectiva culturalmente sensível, cria espaços de "trocas" de ideias, pensamentos, experiências e informações sobre as línguas-culturas em contato, possibilitando a ampliação da visão de mundo do(a) aluno(a) e ressignificando as suas próprias crenças, os seus próprios valores e, portanto, a sua visão de mundo. 
$>\quad$ Deslegitimação dos diversos usos das variedades do português, seja falado ou escrito, seja formal ou informal, em prol de variedades linguísticas socialmente prestigiadas. Cabe-nos, aqui, não só a reflexão, mas, sobretudo, a ação de ensinar o português em uma perspectiva pluricêntrica.

Dito isso, embora este trabalho se trate de uma contribuição inicial que necessita de mais aprofundamento, ele é importante porque mostra ao(à) professor(a) de PLE/L2, principalmente àqueles(as) que estão nos estágios iniciais da sua formação docente, ações que precisam ser ressignificadas.

\section{REFERÊNCIAS}

BRASIL. Instituto Nacional de Estudos e Pesquisas Anísio Teixeira (INEP). Documento base do exame Celpe-Bras [recurso eletrônico]. Brasília, DF: INEP, 2020. Disponível em: https://www.ufrgs.br/acervocelpebras/arquivos/manuais/documento-base-do-exame-celpebras. Acesso em: 18 jun. 2021.

BRASIL. Instituto Nacional de Estudos e Pesquisas Educacionais Anísio Teixeira (INEP). A redação no Enem 2020: cartilha do participante. Brasília, DF: INEP, 2020. Disponível em: https://download.inep.gov.br/publicacoes/institucionais/avaliacoes_e_exames_da_educacao_b asica/a_redacao_do_enem_2020_-_cartilha_do_participante.pdf. Acesso em: 18 jun. 2021.

CANDAU, V. M. Direitos humanos, educação e interculturalidade: as tensões entre igualdade e diferença. Revista brasileira de educação, v. 13, n. 37, p. 54, 2008. Disponível em: https://www.scielo.br/j/rbedu/a/5szsvwMvGSVPkGnWc67BjtC/?format=pdf\&lang=pt. Acesso em: 06 ago. 2021.

CRUZ, S O. Fiz um blog, e daí? Uma experiência sobre o ensino e a formação inicial de professores de português como língua estrangeira/segunda língua em perspectiva intercultural e crítica. 2019. 263 f. Dissertação (Mestrado em Língua e Cultura) - Programa de PósGraduação em Língua e Cultura, Instituto de Letras, Universidade Federal da Bahia (UFBA), Salvador, BA, 2019.

MENDES, E. Aprender a ser e a viver com o outro: materiais didáticos interculturais para o ensino de Português LE/L2. In: SCHEYERL, D. C. M.; SIQUEIRA, S. Materiais didáticos para o ensino de línguas na contemporaneidade: contestações e proposições. Salvador, BA: Editora da Universidade Federal da Bahia (EDUFBA), 2012.

MENDES, E. Abordagem Comunicativa Intercultural (ACIN): uma proposta para ensinar e aprender língua no diálogo de culturas. 2004. 432 f. Tese (Doutorado em Linguística Aplicada) - Universidade Estadual de Campinas (UNICAMP), Campinas, SP, 2004. Disponível em: https://repositorio.unicamp.br/jspui/handle/REPOSIP/269430. Acesso em: 06 ago. 2021. 
MENDES, E. Língua, Cultura e formação de Professores: Por uma Abordagem de Ensino Intercultural. In: MENDES, E.; CASTRO, M. L. S. (org.). Saberes em português: ensino e formação docente. Campinas, SP: Pontes, 2008.

MENDES, E. O português como língua de mediação cultural: por uma formação intercultural de professores e alunos de PLE. In: MENDES, E. (org.) Diálogos Interculturais: ensino e formação em português língua estrangeira. Campinas, SP: Pontes Editores, 2011. p. 137-158.

RAYO, J. T. Educação em direitos humanos: rumo a uma perspectiva global. Ed. Artmed, 2004.

SOUZA, M. I.; FLEURI, R. M. Entre limites e limiares de culturas: educação na perspectiva intercultural. In: FLEURI, R. M. Educação intercultural: mediações necessárias. Rio de Janeiro: DP\&A, 2003. p. 68.

\section{Como referenciar este artigo}

CRUZ, S. O. A A produção escrita em sala de aula de Português como Língua Estrangeira/Segunda Língua: quando e como intervir. Rev. EntreLínguas, Araraquara, v. 7, n. esp. 6, e021139, dez. 2021. e-ISSN: 2447-3529. DOI: https://doi.org/10.29051/el.v7iesp.6.15381

Submetido em: $15 / 08 / 2021$

Revisões requeridas em: 01/10/2021

Aprovado em: 16/11/2021

Publicado em: 28/12/2021 